\title{
Ring Expansion Tetrahydropyrimidin-2-ones into Tetrahydro-1H-1,3-diazepin-2-ones: a Theoretical Study
}

\author{
Anatoly D. Shutalev* and Anastasia A. Fesenko
}

Moscow Technological University, 86 Vernadsky Avenue, 119571 Moscow, Russian Federation

\begin{abstract}
A plausible mechanism for the nucleophile-mediated ring expansion of 4-chloromethyl-1,2,3,4tetrahydropyrimidin-2-one into 2,3,6,7-tetrahydro-1H-1,3-diazepin-2-ones based on DFT calculations at B3LYP/6-31+G(d,p) level is discussed. This mechanism involves the following subsequent steps: $\mathrm{N}_{(1)} \mathrm{H}$ deprotonation under the action of nucleophile, intramolecular nucleophilic substitution of the chlorine atom to give cyclopropane bicyclic intermediate, nucleophile-promoted cyclopropane ring opening leading to 2,5-dihydro-1H-1,3-diazepin-2-one, and addition of nucleophiles to the $\mathrm{C}=\mathrm{N}$ bond to afford the final diazepinones.
\end{abstract}

\section{Keywords}

Tetrahydropyrimidin-2-ones; Tetrahydro-1H-1,3-diazepin-2-ones; Ring expansion; Nucleophiles; DFT calculations; Reaction mechanism

\section{Introduction}

Monocyclic tetrahydro-1H-1,3-diazepin-2-ones, particularly alkyl 2-oxo-2,3,6,7-tetrahydro-1H-1,3diazepine-5-carboxylates (e.g. 1; Figure 1), are the representatives of rare heterocyclic scaffold. ${ }^{1,2}$

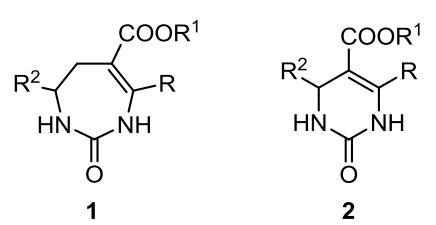

Figure 1. Structures of Biginelli compounds 2 and their seven-membered homo-analogues 1.

In contrast to their six-membered analogues, so-called Biginelli compounds (e.g. 2), ${ }^{3}$ which are readily available and widely studied heterocycles with remarkable biological activities, ${ }^{4,5}$ diazepines 1 
remain practically unknown. Some of them were shown to be useful in the treatment of cardiovascular disorders. ${ }^{6}$ However, extensive biological studies and synthetic applications of these heterocycles are hampered by their extremely low availability.

The only described synthesis of diazepines 1 involves the reaction of ring expansion of methyl- or ethyl-4-chloromethyl-6-methyl-2-oxo-1,2,3,4-tetrahydropyrimidine-5-carboxylates 3a,b under the action of nucleophilic reagents (Scheme 1). ${ }^{6,7}$

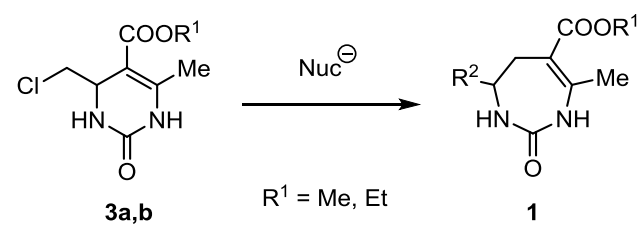

Scheme 1. Synthesis of 1,3-diazepines 1 from their pyrimidine precursors 3a,b.

Principal limitations of this method are poor accessibility and low diversity of starting pyrimidines. The reported synthesis of the latter are specific and cannot be applied for the preparation of target pyrimidines with other substituents at $\mathrm{C} 4, \mathrm{C} 5$ and $\mathrm{C} 6$ positions. ${ }^{7 \mathrm{c}, \mathrm{d}}$

Recently, we have developed a general five-step approach to various 5-functionalized 4chloromethyl-, 4-mesyloxymethyl- and 4-tosyloxymethyl-1,2,3,4-tetrahydropyrimidin-2-ones 4a-c and demonstrated that these compounds can be used for the synthesis of a number of tetrahydro-1H-1,3diazepin-2-ones 5 via nucleophile-mediated ring expansion reaction. ${ }^{8}$

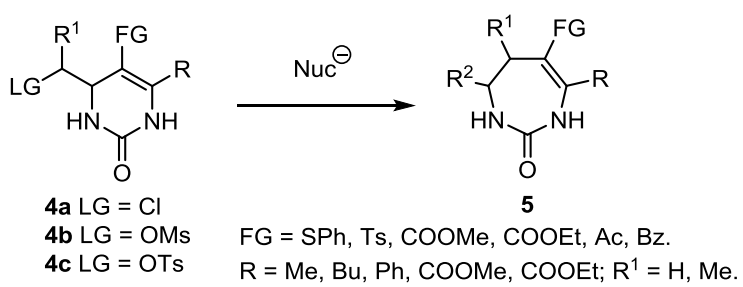

Scheme 2. Ring expansion of tetrahydropyrimidin-2-ones 4a-c into 1,3-diazepines 5.

It is of great importance to study mechanism of the above transformation and related ring expansion reactions of nitrogen-containing heterocycles (1,4-dihydropyridines ${ }^{9}$ and 9,10 -dihydroacridines ${ }^{10}$ ) with $\mathrm{HN}-\mathrm{C}=\mathrm{C}-\mathrm{C}-\mathrm{C}-\mathrm{LG}$ moiety $(\mathbf{A}, \text { Scheme } 3)^{11}$ 

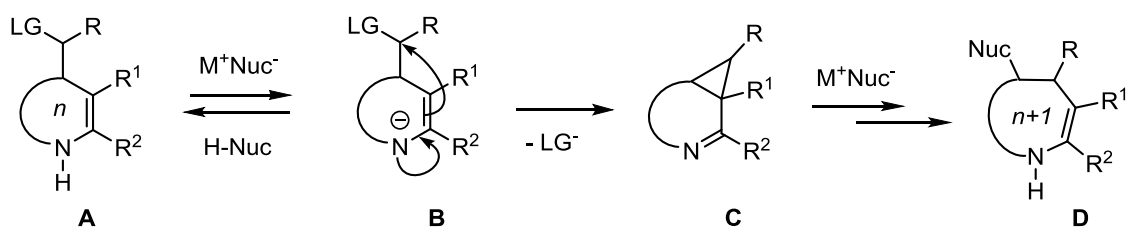

$L G=$ leaving group, $\mathrm{M}^{+} \mathrm{Nuc}^{-}=$nucleophilic reagent

Scheme 3. Proposed one-carbon atom ring expansion pathway.

The reported data indicate that the basicity of nucleophile plays an important role for initiation of all these reactions, since they start from the abstraction of proton from $\mathrm{NH}$ group to give anion $\mathbf{B}$. Subsequent intramolecular substitution of good-leaving group results in bicyclic intermediates $\mathbf{C}$ whose transformations via cyclopropane ring opening lead to ring expansion products $\mathbf{D}$.

However, a general proposed mechanism of the ring expansion outlined in Scheme 3 was based mainly on speculative insights. No experimental evidence of the formation of cyclopropane intermediates $\mathbf{C}$ was reported. It should be noted that the reaction of ring expansion of $\mathrm{N}_{(1)}$-unsubstituted tetrahydropyrimidines to tetrahydro-1,3-diazepines could proceed not only via cyclopropane intermediates (Scheme 4, route a) but also via aziridine ones (route b). Ring expansion reactions involving aziridine intermediates are well documented. ${ }^{12}$

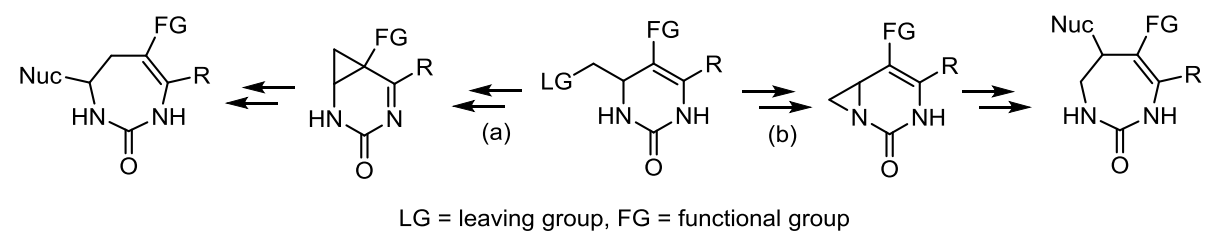

Scheme 4. Two possible pathways of one-carbon atom ring expansion of pyrimidines.

Obviously, formation of 7- or 6-substituted diazepines could be expected following pathway (a) or (b), respectively. Our experimental and reported data showed that the only isolated products were 7substituted diazepines, which proves that the reaction proceeds via pathway (a). Thus, we attempted to rationalize the mechanism of the pyrimidine ring expansion including the reason of exclusive formation of cyclopropane intermediates. Herein we describe this mechanism based on computational data. 


\section{Results and discussion}

The calculations were performed for nucleophile-mediated ring expansion reaction of 4-chloromethyl1,2,3,4-tetrahydropyrimidin-2-one as a model compound. The geometry optimizations of all key stationary points were carried out at the B3LYP level of theory using Gaussian 09 suite of quantum chemical programs. ${ }^{13}$ Pople's basis sets, $6-31+\mathrm{G}(\mathrm{d}, \mathrm{p})$, was employed for geometry optimization in the gas phase and in solution. The effect of continuum solvation was incorporated using the polarizable continuum model. Since MeCN was the typical solvent in the reactions studied, we chose the dielectric constant of $\mathrm{MeCN}(\varepsilon=36.6)$ in the condensed-phase calculations. Enthalpies and Gibbs free energies were obtained by adding unscaled zero-point vibration energy corrections (ZPVE) and thermal contributions to the energies. All transition states were optimized and characterized as a first order saddle point by harmonic vibration frequency analysis. The only one imaginary frequency of the firstorder saddle point was subjected to visual inspection to examine whether it represented the desired reaction coordinate. The intrinsic reaction coordinate (IRC) analysis was performed to authenticate that the transition state pertains to the desired reaction coordinate. The IRC calculations were carried out at the B3LYP/6-31+G(d,p) level of theory.

We performed the B3LYP/6-31+G(d,p) calculations for both routes (a and b) of reaction of compound 6 with cyanide-ion in the gas phase and in $\mathrm{MeCN}$ solution (Scheme 5).

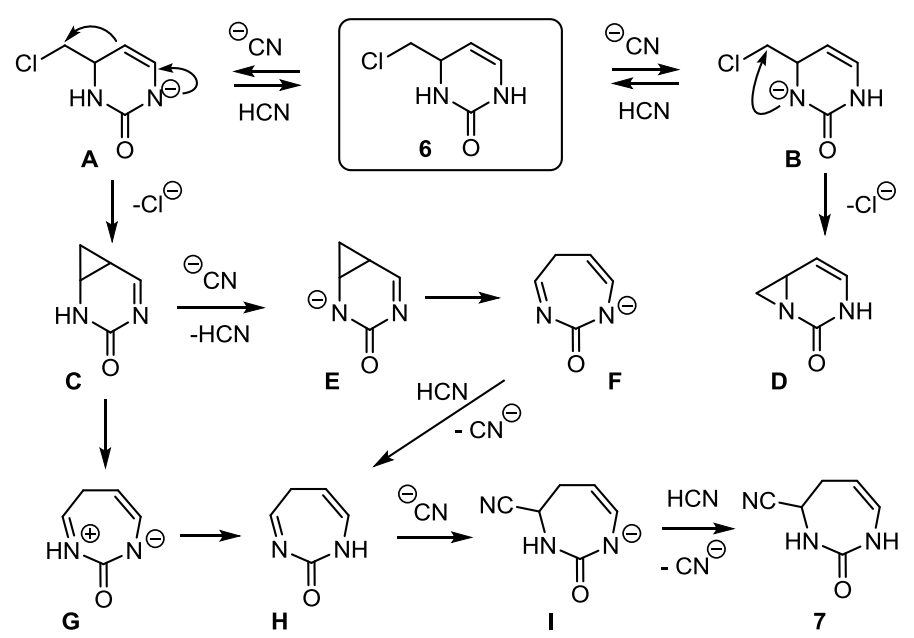

Scheme 5. Two plausible pathways of the ring expansion of pyrimidine 6 into diazepine 7 under the action of cyanide-anion. 
Three principal steps for both the proposed pathways were calculated: (a) deprotonation of $\mathrm{N}_{(1)} \mathrm{H}$ and $\mathrm{N}_{(3)} \mathrm{H}$ in $\mathbf{6}$ under the action of nucleophile resulting in the corresponding anions $\mathbf{A}$ and $\mathbf{B}$; (b) formation of cyclopropane or aziridine bicyclic intermediates $\mathbf{C}$ and $\mathbf{D}$ from anions $\mathbf{A}$ and $\mathbf{B}$, respectively; (c) cyclopropane ring opening in intermediate $\mathbf{C}$ to give ring expansion products followed by their transformation into the final diazepinone 7.

Calculations showed that deprotonation of the $\mathrm{N}_{(1)} \mathrm{H}$ group to give anion $A$ was much more preferable than formation of anion $\mathbf{B}$. Higher stability of anion $\mathbf{A}$ compared with $\mathbf{B}(\Delta \mathrm{G}=5.29 \mathrm{kcal} / \mathrm{mol}$ in the gas phase and $4.09 \mathrm{kcal} / \mathrm{mol}$ in $\mathrm{MeCN}$ ) can be explained by effective delocalization of negative charge in this anion. Thus, the equilibrium concentration of anion $\mathbf{B}$ leading to aziridine intermediate $\mathbf{D}$ (route b) is extremely low, therefore the ring expansion proceeds via cyclopropane intermediate $\mathbf{C}$ (route a).

Intramolecular nucleophilic substitution of chlorine in the most stable conformations of pyrimidine anions $\mathbf{A}$ and $\mathbf{B}$ with antiperiplanar relationship between chlorine and the $\mathrm{C} 5$ or $\mathrm{N}_{(3)}$ atoms, respectively, lead to intermediates $\mathbf{C}$ and $\mathbf{D}$. For both reactions relatively low activation barriers $(\Delta \mathrm{G}=8.04$ and 9.10 $\mathrm{kcal} / \mathrm{mol}$ in the gas phase, 8.74 and $9.52 \mathrm{kcal} / \mathrm{mol}$ in $\mathrm{MeCN}$, respectively) and a decrease in the Gibbs free energies were found (Figure 2).

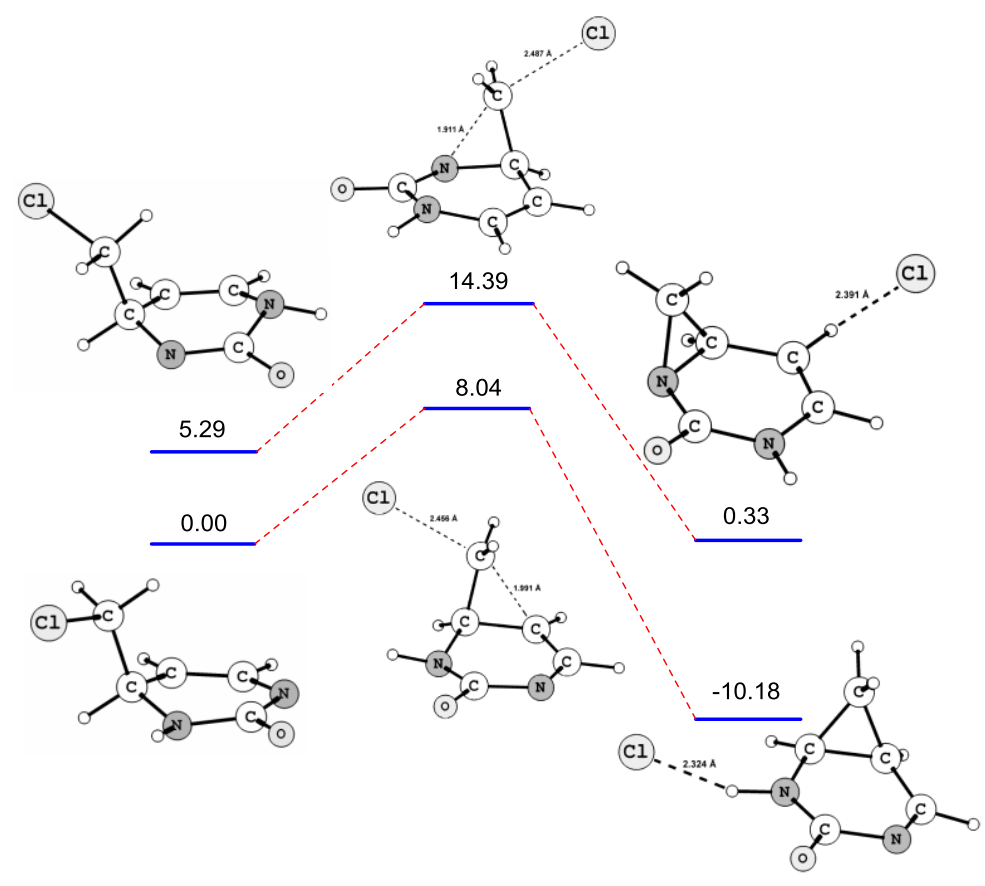

Figure 2. Gibbs free energy profiles (B3LYP/6-31+G(d,p)) for cyclopropane and aziridine intermediates formation via intramolecular nucleophilic substitution of chlorine in $\mathrm{N}_{(1)}$ - and $\mathrm{N}_{(3)}$-anions of 4chloromethyl-1,2,3,4-tetrahydropyrimidin-2-one (6) in gas phase. Free energies in kcal/mol at $298 \mathrm{~K}$ and $1 \mathrm{~atm}$. 
Under basic conditions, bicycle $\mathbf{C}$ can transform into intermediate dihydrodiazepinone $\mathbf{H}$ following two possible pathways (Scheme 5): (1) NH deprotonation followed by ring expansion (C $\rightarrow \mathbf{E} \rightarrow \mathbf{F} \rightarrow$ $\mathbf{H})$ or (2) electrocyclic opening of cyclopropane $\operatorname{ring}(\mathbf{C} \rightarrow \mathbf{G} \rightarrow \mathbf{H})$. The energy barrier $\Delta \mathrm{G}$ for transformation of $\mathbf{C}$ into $\mathbf{G}$ was found to be $10.31 \mathrm{kcal} / \mathrm{mol}$ in the gas phase and $8.12 \mathrm{kcal} / \mathrm{mol}$ in $\mathrm{MeCN}$. In contrast, anion $\mathbf{E}$ resulted from $\mathrm{NH}$ deprotonation of $\mathbf{C}$ is extremely unstable. This anion undergoes ring expansion to give diazepine anion $\mathbf{F}$ without energy barrier $(\Delta \mathrm{G}=0 \mathrm{kcal} / \mathrm{mol})$ in the gas phase or with a very low barrier $(\Delta \mathrm{G}=0.06 \mathrm{kcal} / \mathrm{mol})$ in $\mathrm{MeCN}$. Further detailed calculations using $\mathrm{CN}$-anion as a base showed that the pre-reaction complex of cyclopropane intermediate $\mathbf{C}$ with this anion undergoes both the zero-bridge cleavage and NH deprotonation with an activation barrier of $\Delta \mathrm{G}=4.45 \mathrm{kcal} / \mathrm{mol}$ (the gas phase, $298 \mathrm{~K}, 1 \mathrm{~atm}$ ) to give the post-reaction complex of anion $\mathbf{F}$ with HCN. Ring expansion of the pre-reaction complex of intermediate $\mathbf{C}$ and $\mathrm{CN}$-anion in $\mathrm{MeCN}$ solution proceeds via zero-bridge cleavage with an energy barrier of $\mathrm{G}=6.17 \mathrm{kcal} / \mathrm{mol}$ to provide the complex $\mathbf{G} \cdot \mathrm{CN}^{-}$. The initial ring expansion products further form dihydrodiazepinone $\mathbf{H}$ followed by the addition of $\mathrm{HCN}$ to the $\mathrm{C}=\mathrm{N}$ double bond to give the target diazepine 27. It should be noted that transformation of bicycle $\mathbf{C}$ into diazepine $\mathbf{H}$ promoted by bases is a thermodynamically favorable process with $\Delta \mathrm{G}=-9.86 \mathrm{kcal} / \mathrm{mol}$ and $\Delta \mathrm{G}=-8.16 \mathrm{kcal} / \mathrm{mol}$ in the gas phase and MeCN, respectively (298 K, $1 \mathrm{~atm})$.

We believe that the nucleophile-promoted ring expansion of 5-functionalized pyrimidines 4a-c into diazepines 5 proceeds, in general, analogously to that described above for compound 6 (Scheme 6). However, we suppose that the presence of an electron-withdrawing group at the C5 in the starting compounds may assist the reaction.
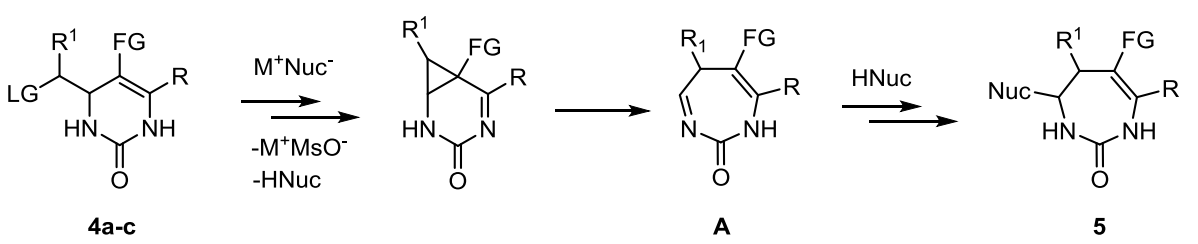

Scheme 6. Plausible pathway of ring expansion of pyrimidines 4a-c under action of nucleophiles.

According to the above discussed mechanism, transformation of pyrimidinones 4a-c into diazepinones $\mathbf{5}$ includes two consecutive reaction sets. The first set is the pyrimidine ring expansion controlled only by basicity of the nucleophile to result in dihydrodiazepinones $\mathbf{A}$, and the second is nucleophilic addition to the latter determined by nucleophilicity of the nucleophile to give the final products. 


\section{Conclusion}

A plausible mechanism of pyrimidine ring expansion in 4-chloromethyl-1,2,3,4-tetrahydropyrimidin-2one based on the DFT calculations at B3LYP/6-31+G(d,p) level was proposed. This mechanism involved the following subsequent steps: $\mathrm{N}_{(1)} \mathrm{H}$ deprotonation under the action of nucleophile, intramolecular nucleophilic substitution of chlorine atom to give the cyclopropane bicyclic intermediate, nucleophile-mediated cyclopropane ring opening leading to 2,5-dihydro-1H-1,3-diazepin-2-one, and addition of nucleophiles to the $\mathrm{C}=\mathrm{N}$ bond to afford the final diazepinones.

\section{Acknowledgments}

This research was financially supported by the Russian Foundation for Basic Research (Grant No. 1503-07564).

\section{References}

1. For reviews on 1,3-diazepines, see: (a) De Borggraeve, W. M.; Van den Bogaert, A. M. 1,3Diazepines. In Comprehensive Heterocyclic Chemistry III; Katritzky, A. R., Ramsden, C. A., Scriven E. F. V., Taylor, R. J. K., Eds.; Elsevier: Oxford, 2008; Vol. 13, pp 161-181; (b) Herr, R. J. Seven-Membered Hetarenes with Two or More Heteroatoms. In Science of Synthesis; Weinreb, S. M., Ed.; Georg Thieme Verlag: Stuttgart, 2004; Vol. 17, pp 929-972; (c) Sharp, J. T. Sevenmembered ring compounds containing nitrogen in the ring. In Rodd's Chemistry of Carbon Compounds; Sainsbury, M., Ed.; Elsevier: Amsterdam, 1999; Second Supplements to the 2nd Edition, Vol. IV, Part K, pp 153-232; (d) Boyd, G. V. Aromatic 7-ring systems with two or more heteroatoms. In Houben-Weyl: Methods of Organic Chemistry; Schumann, E., Ed.; Georg Thieme Verlag: Stuttgart, 1997; Vol. E9d, pp 299-508; (e) Sharp, J. T. Seven-membered Rings with Two or More Heteroatoms. In Comprehensive Heterocyclic Chemistry; Katritzky, A. R., Rees, C. W., Eds.; Elsevier, CD-ROM version, 1997; Vol. 7, pp 593-651; (f) Le Count, D. J. 1,3-Diazepines. In Comprehensive Heterocyclic Chemistry II; Katritzky, A. R., Rees, C. W., Scriven, E. F. V., Eds.; Elsevier: Oxford, 1996; Vol. 9, pp 139-150; (g) Popp, F. D., Noble, A. C. The Chemistry of Diazepines. In Adv. Heterocycl. Chem; Katritzky, A. R., Boulton, A. J., Eds.; Academic Press: New York and London, 1967; Vol. 8, pp 21-82.

2. For recent examples on tetrahydro-1H-1,3-diazepin-2-ones synthesis, see: (a) McCreanor, N. G.; Stanton, S.; Bower, J. F. J. Am. Chem. Soc. 2016, 138, 11465-11468; (b) Anumandla, D.; Littlefield, R.; Jeffrey, C. S. Org. Lett. 2014, 16, 5112-5115; (c) Siddiqui, I. R.; Srivastava, A.; 
Shamim, S.; Srivastava, A.; Shireen; Waseem, M. A.; Singh, R. K. P. Synlett 2013, 24, 2586-2590;

(d) Kim, M.; Gajulapati, K.; Kim, C.; Jung, H. Y.; Goo, J.; Lee, K.; Kaur, N.; Kang, H. J.; Chung, S. J.; Choi, Y. Chem. Commun. 2012, 48, 11443-11445; (e) Kanno, E.; Yamanoi, K.; Koya, S.; Azumaya, I.; Masu, H.; Yamasaki, R.; Saito, S. J. Org. Chem. 2012, 77, 2142-2148; (f) Okano, A.; Oishi, S.; Fujii, N.; Ohno, H.; Tanaka, T. J. Org. Chem. 2010, 75, 3396-3400; (g) Ludek, O. R.; Schroeder, G. K.; Liao, C.; Russ, P. L.; Wolfenden, R.; Marquez, V. E. J. Org. Chem. 2009, 74, 6212-6223.

3. For reviews on Biginelli compounds, see: (a) Singh, Kawaljit; Singh, Kamaljit. Biginelli Condensation: Synthesis and Structure Diversification of 3,4-Dihydropyrimidin-2(1H)-one Derivatives. In Adv. Heterocycl. Chem.; Katritzky, A. R., Ed.; Elsevier: Amsterdam, 2012; Vol. 105, pp 223-308; (b) Kolosov, M. A.; Orlov, V. D.; Beloborodov, D. A.;'Dotsenko, V. V. Mol Divers 2009, 13, 5-25; (c) Kappe, C. O. The Biginelli reaction. In Multicomponent reactions; Zhu, J., Bienaymé, H., Eds.; John Wiley: New York, 2005; pp 95-120; (d) Kappe, C. O.; Stadler, A. The Biginelli dihydropyrimidine synthesis. In Organic Reactions; Overman, L. E., Ed.; John Wiley: New York, 2004; Vol. 63, pp 1-116; (e) Kappe, C. O. Acc. Chem. Res. 2000, 33, 879-888; (f) Kappe, C. O. Tetrahedron 1993, 49, 6937-6963; (g) Chen, Q.; Jiang, L.-L.; Chen, C.-N.; Yang, G.F. J. Heterocycl. Chem. 2009, 46, 139-148.

4. For reviews on biological activities of Biginelli compounds, see: (a) Wan, J.-P.; Pan, Y. Mini-Rev. Med. Chem. 2012, 12, 337-349. (b) Kappe, C. O. Eur. J. Med. Chem. 2000, 35, 1043-1052.

5. (a) Atwal, K. S.; Swanson, B. N.; Unger, S. E.; Floyd, D. M.; Moreland, S.; Hedberg, A.; O’Reilly, B. C. J. Med. Chem. 1991, 34, 806-811; (b) Grover, G. J.; Dzwonczyk, S.; McMullen, D. M.; Normandin, D. E.; Parham, C. S.; Sleph, P. G.; Moreland, S. J. Cardiovasc. Pharmacol. 1995, 26, 289-294; (c) Haggarty, S. J.; Mayer, T. U.; Miyamoto, D. T.; Fathi, R.; King, R. W.; Mitchison, T. J.; Schreiber, S. L. Chem. Biol. 2000, 7, 275-286; (d) Nagarathnam, D.; Miao, S. W.; Lagu, B.; Chiu, G.; Fang, J.; Dhar, T. G. M.; Zhang, J.; Tyagarajan, S.; Marzabadi, M. R.; Zhang, F.Q.; Wong, W. C.; Sun, W. Y.; Tian, D.; Wetzel, J. M.; Forray, C.; Chang, R. S. L.; Broten, T. P.; Ransom, R. W.; Schorn, T. W.; Chen, T. B.; O’Malley, S.; Kling, P.; Schneck, K.; Benedesky, R.; Harrell, C. M.; Vyas, K. P.; Gluchowski, C. J. Med. Chem. 1999, 42, 4764-4777.

6. Baldwin, J. J.; McClure, D. E.; Claremon, D. A. U.S. Patent 4,677,102, 1987; Chem. Abstr. 1988, 109, 54794.

7. (a) Bullock, E.; Garter, R. A.; Gregory, B.; Shields, D. C. Chem. Commun. 1972, 97-98; (b) Ashby, J.; Griffiths, D. Chem. Commun. 1974, 607-608; (c) Ashby, J.; Griffiths, D. J. Chem. Soc., Perkin 
Trans. 1 1975, 657-662; (d) Bullock, E.; Garter, R. A.; Cochrane, R.; Gregory, B.; Shields, D. C. Can. J. Chem. 1977, 55, 895-905; (e) Claremon, D. A.; Rosenthal, S. A. Synthesis 1986, 664-665.

8. (a) Fesenko, A. A.; Tullberg, M. L.; Shutalev, A. D. Tetrahedron 2009, 65, 2344-2350; (b) Fesenko, A. A.; Shutalev, A. D. Tetrahedron 2011, 67, 6876-6882; (c) Fesenko, A. A.; Trafimova, L. A.; Shutalev, A. D. Org. Biomol. Chem. 2012, 10, 447-462; (d) Fesenko, A. A.; Trafimova, L. A.; Albov, D. V.; Shutalev, A. D. Tetrahedron Lett. 2015, 56, 1317-1321; (e) Fesenko, A. A.; Grigoriev, M. S.; Shutalev, A. D. J. Org. Chem. 2017, 82, 8085-8110.

9. (a) Gregory, B.; Bullock, E.; Chen, T.-S. Can. J. Chem. 1985, 63, 843-848; (b) Claremon, D. A.; McClure, D. E.; Springer, J. P.; Baldwin, J. J. J. Org. Chem. 1984, 49, 3871-3874; (c) Gregory, B.; Bullock, E.; Chen, T.-S. Can. J. Chem. 1979, 57, 44-52; (d) Ashby, J.; Cort, L. A.; Elvidge, J. A. J. Chem. Soc. C 1968, 2311-2317; (e) Brignell, P. J.; Bullock, E.; Eisner, U.; Gregory, B.; Johnson, A. W.; Williams, H. J. Chem. Soc. 1963, 4819-4827.

10. Groth, U.; Richter, L.; Schöllkopf, U. Liebigs Ann. Chem. 1992, 199-202.

11. For reviews on ring expansion reaction, see: (a) Stach, H.; Hesse, M. Tetrahedron 1988, 44, 15731590; (b) Hesse, M. Ring Enlargement in Organic Chemistry, VCH: Weinheim, 1991; (c) Roxburgh, C. J. Tetrahedron 1993, 49, 10749-10784; (d) Kantorowski, E. J.; Kurth, M. J. Tetrahedron 2000, 56, 4317-4353; (e) Mack, D. J.; Njardarson, J. T. ACS Catal. 2013, 3, 272-286; (f) Fesenko, A. A.; Shutalev, A. D. Chem. Heterocycl. Compd. 2013, 49, 827-848.

12. For reviews on ring expansion reactions via aziridine intermediates, see: (a) Tymoshenko, D. O. ARKIVOC 2011, 2011 (i), 329-345; (b) Ferret, H.; Déchamps, I.; Pardo, D. G.; Hijfte, L. V.; Cossy, J. ARKIVOC 2010, 2010 (viii), 126-159.

13. Gaussian 09, Revision D.01: Frisch, M. J.; Trucks, G. W.; Schlegel, H. B.; Scuseria, G. E.; Robb, M. A.; Cheeseman, J. R.; Scalmani, G.; Barone, V.; Mennucci, B.; Petersson, G. A.; Nakatsuji, H.; Caricato, M.; Li, X.; Hratchian, H. P.; Izmaylov, A. F.; Bloino, J.; Zheng, G.; Sonnenberg, J. L.; Hada, M.; Ehara, M.; Toyota, K.; Fukuda, R.; Hasegawa, J.; Ishida, M.; Nakajima, T.; Honda, Y.; Kitao, O.; Nakai, H.; Vreven, T.; Montgomery, J. A., Jr.; Peralta, J. E.; Ogliaro, F.; Bearpark, M.; Heyd, J. J.; Brothers, E.; Kudin, K. N.; Staroverov, V. N.; Kobayashi, R.; Normand, J.; Raghavachari, K.; Rendell, A.; Burant, J. C.; Iyengar, S. S.; Tomasi, J.; Cossi, M.; Rega, N.; Millam, N. J.; Klene, M.; Knox, J. E.; Cross, J. B.; Bakken, V.; Adamo, C.; Jaramillo, J.; Gomperts, R.; Stratmann, R. E.; Yazyev, O.; Austin, A. J.; Cammi, R.; Pomelli, C.; Ochterski, J. W.; Martin, R. L.; Morokuma, K.; Zakrzewski, V. G.; Voth, G. A.; Salvador, P.; Dannenberg, J. J.; Dapprich, S.; Daniels, A. D.; Farkas, Ö.; Foresman, J. B.; Ortiz, J. V.; Cioslowski, J.; Fox, D. J. , Gaussian, Inc., Wallingford CT, 2013. 